\title{
JATOS DE BAIXOS NÍVEIS A LESTE DOS ANDES: COMPARAÇÃO ENTRE DUAS REANÁLISES
}

\author{
SANTOS, Diego Felipe dos- dfsantos17@hotmail.com \\ Universidade Federal de Itajubá / UNIFEI \\ REBOITA, Michelle Simões - reboita@gmail.com \\ Universidade Federal de Itajubá / UNIFEI
}

\begin{abstract}
RESUMO: O estudo apresenta uma comparação da ocorrência de jatos de baixos níveis (JBN) a leste dos Andes, registrados na reanálise I do NCEP-NCAR (resolução horizontal de $2,5^{\circ}$ ) e na reanálise ERA-Interim do ECMWF (resolução horizontal de $0,75^{\circ}$ ), no período de 2001 a 2015. Os eventos de JBN foram identificados com o critério 1 de Bonner em oito municípios localizados no centro-sul da América do Sul, região de atuação do sistema. Em Santa Cruz de la Sierra, Mariscal Estigarribia, Trinidad e Foz do Iguaçu, a reanálise do NCEP-NCAR apresenta menor frequência de jatos do que a reanálise ERA-Interim. Em termos de sazonalidade, a reanálise do NCEP-NCAR mostra maior ocorrência de JBN no verão, nos municípios localizados em latitudes mais tropicais (Cobija, Trinidad, Santa Cruz de la Sierra e Robore), enquanto que nos municípios situados nos subtrópicos (Mariscal Estigarribia, Assunção, Curitiba e Foz do Iguaçu), a maior ocorrência aparece no inverno. Por outro lado, a reanálise ERA-Interim mostra maior frequência do JBN no inverno, nos municípios de Santa Cruz de la Sierra e Robore. Em geral, ambas as reanálises indicam que o JBN ocorre preferencialmente entre 06 e 12 UTC. Por fim, com relação à variabilidade interanual, o JBN tende a ser mais frequente em anos de ocorrência de eventos El Niño.
\end{abstract}

PALAVRAS-CHAVES: jato de baixos níveis, América do Sul, reanálise I do NCEP-NCAR, reanálise ERA-Interim

\section{LOW LEVEL JETS EASTERN OF THE ANDES: COMPARISON BETWEEN TWO REANALYSES}

ABSTRACT: This study shows a comparison of the climatology of low level jet (LLJ) eastern of the Andes obtained from the NCEP-NCAR reanalysis I (horizontal resolution of $2.5^{\circ}$ ) and the ERA-Interim reanalysis from ECMWF (horizontal resolution $0.75^{\circ}$ ) in the period 2001-2015. The LLJ were identified with Bonner criterion 1 in eight cities located in the center-south of South America, region of operation of the system. In Santa Cruz de la Sierra, Mariscal Estigarribia, Trinidad and Foz do Iguaçu the NCEP-NCAR reanalysis I register less LLJ events than the ERA-Interim. The NCEP-NCAR reanalysis I show the highest occurrence of LLJ in cities located in more tropical latitudes (Cobija, Trinidad, Santa Cruz de la Sierra and Robore) in summer, while in cities located in more subtropical region (Mariscal Estigarribia, Asuncion, Curitiba and Foz do Iguaçu), in winter. On the other hand, ERA-Interim shows higher LL] frequency in Santa Cruz de la Sierra and Robore during the winter. In general, both reanalysis indicate that LLJ occur more frequently between 6 and 12 UTC. Finally, with respect to the interannual variability, the LLJ tend to have higher frequency in El Niño years.

KEYWORDS: low-level jet, South America, NCEP-NCAR reanalysis I, ERA-Interim

\section{INTRODUÇÃO}

Os jatos de baixos níveis (JBNs) são escoamentos intensos na baixa troposfera (STENSRUD, 1996), cuja velocidade máxima ocorre entre 1 a $2 \mathrm{~km}$ de altura (máximo em aproximadamente $850 \mathrm{hPa}$ ), ocupando uma região estreita horizontalmente. Esses jatos podem ter direção zonal ou meridional o que depende dos processos associados à sua formação. Os JBNs estão presentes em diferentes regiões do globo (STENSRUD, 1996) como, por exemplo, a oeste (RAHN; GARREAUD, 2013) e leste (MARENGO et al., 2004) da cordilheira dos 
Andes na América do Sul, no mar do Caribe (DURÁN-QUESADA, 2012), a oeste e leste das montanhas Rochosas na América do Norte (JIANG et al., 2007) etc.

Com relação aos JBNs a leste dos Andes, esses são caracterizados por um escoamento meridional que se dirige da Amazônia para os subtrópicos da América do Sul (MARENGO et al., 2004; VERA et al., 2006; NASCIMENTO et al., 2016). O jato é mais extenso meridionalmente do que zonalmente e sua largura pode chegar a aproximadamente $500 \mathrm{~km}$ (MARENGO et al., 2004). Uma revisão sobre os mecanismos físicos de formação dos JBNs no globo é apresentada em Stensrud (1996), já um resumo dos possíveis mecanismos associados à ocorrência do jato de baixos níveis (JBN) a leste dos Andes é citado por Vera et al. (2006) e reproduzidos aqui: (1) a barreira topográfica ajuda a canalizar os ventos alísios provenientes do Atlântico Norte Tropical e que atravessam a bacia Amazônica em direção aos subtrópicos, (2) efeito puramente local, por existência da topografia, dirigido pela dinâmica seca, mas possivelmente modificado pela convecção úmida nas encostas dos Andes, (3) perturbações ciclônicas no escoamento de oeste no norte da Argentina podem causar variações no campo de pressão contribuindo para que o escoamento se dirija para tal local e (4) propagação de rajadas de vento em baixos níveis da atmosfera do Atlântico Norte em direção a bacia do Prata através da bacia Amazônica.

A fim de explicar os mecanismos citados por Vera et al. (2006), foram utilizadas as ideias de Stensrud (1996) e os resultados de vários estudos sobre os JBNs a leste dos Andes. Com relação ao item (1), estudos numéricos como os de Gandu e Geisler (1991), Insel et al. (2010), Reboita et al. (2012) e Junquas et al. (2016) mostram que o JBN a leste dos Andes existe mesmo sem a barreira topográfica, mas nesse caso não é bem configurado. Na ausência dos Andes, perturbações ciclônicas em baixos níveis nos subtrópicos contribuem para um gradiente de pressão trópicos-subtrópicos e, consequentemente, para a maior ocorrência dos JBNs. Entretanto, como mostrado em Reboita (2008), as perturbações ciclônicas sem os Andes também são mais fracas, pois os distúrbios transientes em níveis médios do Oceano Pacífico em direção ao oceano Atlântico não têm suporte do cavado semi-estacionário formado pela presença dos Andes (SATYAMURTY et al., 1980), o que acaba impactando os distúrbios em superfície e, também, os JBNs.

O item (2) de Vera et al. (2006) pode estar relacionado com o desenvolvimento de circulação de brisa de vale e montanha devido ao aquecimento diferencial entre encostas das montanhas e o ar no mesmo nível nos vales (STENSRUD, 1996). Durante o dia, o ar na face das montanhas aquece mais rapidamente do que o ar no mesmo nível nos vales. Com isso, um escoamento é gerado do vale para a montanha. Durante à noite, a circulação inverte-se e tem-se a brisa de montanha. É válido ressaltar que, em geral, as brisas de montanha são mais vigorosas do que as de vale e isso pode estar associado ao fato do maior número de JBNs identificados no período noturno (06 UTC) por Marengo et al. (2004) nas cercanias de Santa Cruz de la Sierra na Bolívia. De fato, a circulação de brisa de montanha ocorre à noite. Próximo à superfície o escoamento será da montanha para o vale, mas em níveis mais afastados da superfície a célula de circulação terá escoamento da região do vale para a montanha. Em outras palavras, a força de gradiente de pressão ocorre de leste para oeste. Embora a circulação de brisa seja um fenômeno pouco influenciado pela força de Coriolis, como os Andes possuem uma grande 
extensão latitudinal, as circulações de brisa são mais extensas e a força de Coriolis atua no escoamento (defletindo-o para a esquerda de seu movimento) que ganha uma componente para sul, ou seja, a componente sul do JBN.

O item (3), foi proposto, provavelmente pela primeira vez, por Sugahara et al. (1994) quando encontraram na composição do campo de pressão ao nível médio do mar para eventos de JBNs um aprofundamento do cavado em superfície sobre o Paraguai e norte da Argentina, que era ausente na composição dos dias sem JBNs. Seluchi e Marengo (2000) também sugerem que durante o verão austral, a baixa pressão em superfície, localizada em aproximadamente $25^{\circ} \mathrm{S}$ e $65^{\circ} \mathrm{O}$ (a "baixa do Chaco", uma baixa térmica), se intensifica devido ao saldo positivo de radiação. A passagem de um cavado em altos níveis sobre a Argentina muitas vezes contribui para o aprofundamento da baixa do Chaco e com isto intensifica o escoamento de norte. Já Campetella e Vera (2002), através de experimento com modelo numérico, mostraram que o JBN é modulado pela presença dos Andes e por sistemas sinóticos transientes no sul e sudeste da América do Sul. Além disso, a posição dos sistemas de baixa pressão (ciclones) é que modula a orientação do JBN. Se o ciclone está entre a Argentina e Uruguai, o JBN se dirige para essa região, se está na costa do Brasil, o jato desloca-se para tal localidade. Marengo et al. (2004) mencionam que a grande variabilidade da hora preferencial de ocorrência do JBN no inverno pode ser uma outra indicação de que os sistemas transientes sinóticos são importantes para a modulação do JBN, já que no inverno há grande atuação desses e sem hora preferencial de ocorrência. Com relação ao item (4) mencionado por Vera et al. (2006), ocorre uma intensificação dos ventos que adentram a Amazônia e encontram os Andes devido às rajadas (ventos mais intensos) do Atlântico Norte em direção à América do Sul.

Para a identificação dos JBNs, devido à escassez de radiossondagens, se utilizam dados de reanálise. Marengo et al. (2004) usaram a reanálise I do National Center for Environmental Prediction (NCEP-NCAR, KALNAY et al., 1996), entre 1950 e 2000, e identificaram os JBNs através do critério 1 de Bonner (BONNER, 1968). Entre os meses de novembro a fevereiro, há maior frequência de JBN a norte de $20^{\circ} \mathrm{S}$ (na região da Bolívia) enquanto que ao sul dessa latitude os jatos ocorrem ao longo de todo o ano. Nas latitudes mais baixas, os JBNs estão associados com os ventos alísios de nordeste e são mais intensos nos meses de verão (DURÁN-QUESADA et al., 2012). Já ao sul de $20^{\circ}$ $\mathrm{S}$, o ramo oeste do anticiclone subtropical do Atlântico Sul é que favorece a ocorrência do JBN (REBOITA et al., 2010). Na região da Bolívia, na estação quente, os jatos possuem intensidade de cerca de $12 \mathrm{~m} \mathrm{~s}^{-1}$ entre 850 e $900 \mathrm{hPa}$. Nascimento et al. (2016) também realizaram uma climatologia dos JBNs a leste dos Andes usando o critério 1 de Bonner, mas para o período de 1979 a 2008. Nesse estudo, os autores utilizaram a reanálise CFSR do NCEP (SAHA et al., 2010) e consideraram que um determinado dia possuía JBN se os critérios de Bonner fossem satisfeitos concomitantemente em Santa Cruz de la Sierra (Bolívia) e Mariscal Estigarribia (Paraguai) em um dos quatro horários sinóticos (00, 06, 12 e 18 UTC). Além disso, realizaram um estudo dos jatos individualmente para cada um dos dois municípios. Considerando, a primeira análise (ocorrência concomitante em dois locais), $8 \%$ de todos os dias do período de estudo apresentaram ocorrência de JBNs, sendo a maior frequência registrada no inverno seguida do outono, primavera e verão. A análise por municípios também indicou maior frequência de JBNs no inverno. Em Mariscal 
Estigarribia, cerca de $49 \%$ dos dias em estudo apresentaram JBNs, enquanto que em Santa Cruz de la Sierra esse número se reduz para $21 \%$. Os resultados de Nascimento et al. (2016) discordam de Marengo et al. (2014) quando o município analisado é Santa Cruz de la Sierra, pois no primeiro há maior frequência de JBNs no inverno e no segundo, no verão. Nascimento et al. (2016) não discutem as causas das diferenças. Entretanto, sugere-se aqui que essas podem ser devido aos diferentes conjuntos de dados e período de estudo usados pelos autores.

Com relação ao ciclo diurno dos JBNs, para a definição correta, seriam necessários dados observados em ar superior com frequência horária, entretanto como não existe esse conjunto de dados para estudos climatológicos, Marengo et al. (2004) avaliaram a ocorrência dos JBNs nos quatro horários sinóticos da reanálise. O JBN, no verão, é mais frequente às 06 UTC na região de Santa Cruz de la Sierra e entre 06 e 12 UTC nas outras localidades. Resultados similares foram obtidos por Nascimento et al. (2016).

Em termos de variabilidade interanual, os estudos de Silva e Ambrizzi (2006) e Silva et al. (2009) indicam uma relação entre a frequência e intensidade dos JBNs a leste dos Andes com o fenômeno El Niño-Oscilação Sul. Em eventos El Niño (La Niña), os JBNs tendem a ser mais (menos) frequentes e intensos do que a média climatológica. Uma possível explicação para isso seria a intensificação dos ventos alísios de nordeste sobre o continente em anos de El Niño o que, consequentemente, favoreceria os JBNs, de acordo com Silva et al. (2009).

O estudo dos JBNs é importante porque eles além de transportar umidade estão relacionados com a atividade convectiva profunda. A superposição do jato subtropical de altos níveis com o JBN pode desencadear movimentos ascendestes na atmosfera favorecendo a convecção (BEEBE; BATES, 1955; SILVA DIAS, 1987). Esse é o principal mecanismo para o desenvolvimento de sistemas convectivos de mesoescala no norte/nordeste da Argentina, Paraguai, Uruguai e sul do Brasil (SILVA DIAS, 1987). Além disso, o JBN é um dos sistemas que contribuem para a ocorrência da Zona de Convergência do Atlântico Sul (ZCAS), sistema típico de verão. Quando a ZCAS está intensa, o JBN tem sua saída sobre o sudeste do Brasil e quando ela está fraca, sua saída desloca-se para sobre o sul do Brasil e Uruguai (NOGUÉSPEAGLE; MO, 1997).

Marengo et al. (2004) também mencionam que a reanálise do NCEPNCAR subestima o número e a intensidade dos JBNs comparado com observações realizadas por radiossondagens. Algumas das possíveis explicações para isso são que os dados das radiossondagens possuem maior resolução vertical do que a reanálise; a reanálise tende a suavizar os dados e poucas radiossondagens na região a leste dos Andes são assimiladas pelo modelo que gera a reanálise, representando possivelmente mais a circulação produzida pelo modelo do que a situação real (MARENGO et al., 2002, 2004). Para Berbery e Barros (2002), a subestimativa da frequência e intensidade dos JBNs a leste dos Andes com os dados da reanálise I do NCEP-NCAR pode estar associada ao fato de que a reanálise não representa as características de mesoescala dos fenômenos atmosféricos por causa de sua baixa resolução espacial. De fato, na época em que esses dois estudos foram realizados só eram disponíveis pelos centros internacionais de meteorologia reanálises com resolução horizontal de 
$2,5^{\circ} \times 2,5^{\circ}$ de latitude por longitude. No final da década de 2010, o European Centre for Medium-Range Weather Forecasts (ECMWF) passou a disponibilizar a reanálise ERA-Interim (DEE et al., 2011) com resolução horizontal de $0,75^{\circ} \mathrm{x}$ $0,75^{\circ}$, o que permite uma representação mais detalhada dos sistemas atmosféricos. Diante disso, o objetivo do presente trabalho é comparar vários aspectos da climatologia dos JBNs a leste dos Andes entre a reanálise I do NCEP-NCAR e a reanálise ERA-Interim do ECMWF no período de 2001 a 2015. Esse período foi escolhido por possuir maior consistência na assimilação de dados, tendo em vista a utilização de informações de satélite.

\section{DADOS E METODOLOGIA}

\subsection{DADOS}

No presente estudo são utilizadas as variáveis atmosféricas: componente zonal (u) e meridional (v) do vento em 850 e $700 \mathrm{hPa}$ da reanálise I do NCEPNCAR (KALNAY et al., 1996) e da reanálise ERA-Interim (DEE et al., 2011), no período de 2001 a 2015. Ambas as reanálises possuem frequência de 6 horas (00, 06, 12 e 18 UTC), sendo que a resolução horizontal da reanálise do NCEPNCAR é $2,5^{\circ}$ e a da ERA-Interim é $0,75^{\circ}$. Como em Marengo et al. (2004), assumiu-se que o nível de $850 \mathrm{hPa}$ é o mais representativo da circulação dos JBNs a leste dos Andes.

\subsection{CRITÉRIOS PARA IDENTIFICAÇÃO DO JBN}

Os JBNs foram identificados com o critério 1 de Bonner (BONNER, 1968) adaptado para a América do Sul (MARENGO et al., 2004). O critério 1 de Bonner constitui um conjunto de quatro critérios relativos a limiares de vento em 850 e $700 \mathrm{hPa}$, apresentados na Tabela 1.

Tabela 1 - Critério 1 de Bonner aplicado na identificação do JBN a leste dos Andes.

\begin{tabular}{|c|c|}
\hline Critérios & Explicação \\
\hline$V_{850} \geq 12 \mathrm{~m} \mathrm{~s}^{-1}$ & $\begin{array}{c}\text { Intensidade do vento, representada por } \mathrm{V}\left(\mathrm{m} \mathrm{s}^{-1}\right) \text {, em } 850 \mathrm{hPa} \text {, } \\
\text { deve ser maior ou igual a } 12 \mathrm{~m} \mathrm{~s}^{-1} \text {. }\end{array}$ \\
\hline$V_{850}-V_{700}>6 \mathrm{~m} \mathrm{~s}^{-1}$ & $\begin{array}{l}\text { Cisalhamento vertical do vento, ou seja, a diferença entre a } \\
\text { intensidade do vento nos níveis de } 850 \text { e } 700 \mathrm{hPa} \text { deve ser maior } \\
\text { do que } 6 \mathrm{~m} \mathrm{~s}^{-1} \text {. Isso indica que a intensidade do vento em } 850 \mathrm{hPa} \\
\text { é maior do que em } 700 \mathrm{hPa} \text {. } \\
\text { Componente meridional do vento, representada por } \mathrm{v}\left(\mathrm{m} \mathrm{s}^{-1}\right) \text {, em }\end{array}$ \\
\hline $\mathrm{v}_{850}<0 \mathrm{~m} \mathrm{~s}^{-1}$ & $\begin{array}{c}850 \mathrm{hPa} \text {, deve ser negativa. Isso garante que o sentido dessa } \\
\text { componente seja de norte em direção ao sul. }\end{array}$ \\
\hline$\left|v_{850}\right|>\left|u_{850}\right|$ & $\begin{array}{l}\text { Módulo da componente meridional do vento }(\mathrm{v}) \text { dever ser maior do } \\
\text { que o módulo da componente zonal do vento }(\mathrm{u}) \text {. Em outras } \\
\text { palavras, a componente meridional é mais intensa do que a zonal. }\end{array}$ \\
\hline
\end{tabular}

O critério 1 de Bonner foi aplicado para todos os pontos de grade e nos quatro horários sinóticos (aqui não foi levado em consideração a ocorrência diária como em Nascimento et al., 2016) da reanálise I do NCEP-NCAR e da reanálise do ERA-Interim. Entretanto, antes disso, o método apresentado foi validado utilizando a reanálise do NCEP-NCAR no mesmo período do estudo de 
Marengo et al. (2004), isto é, de 1950 a 2000. Como os resultados desses autores foram reproduzidos (figuras não mostradas), garantiu-se que a utilização dos critérios estava correta.

\subsection{PROCEDIMENTOS PARA ANÁLISE}

Na primeira parte dos resultados são apresentadas as climatologias da intensidade e direção do vento em $850 \mathrm{hPa}$ obtidas com a reanálise do NCEPNCAR e com a ERA-Interim (Figura 2). Com os critérios descritos na seção 2.2, foi possível identificar o número de ocorrência de JBN em pontos de grade, entre 2001 e 2015, na América do Sul, indicando as regiões com maior frequência desse sistema atmosférico. Esse resultado é mostrado na forma de mapa (Figura 3). Ressalta-se aqui, que esse é o primeiro estudo que apresenta a climatologia dos JBNs a leste dos Andes nesse formato. Para facilitar a comparação entre as reanálises, os mesmos locais indicados na Figura 2 de Marengo et al. (2004) são utilizados no presente estudo (Figura 1 e Tabela 2). Em tais localidades são computados o total de JBNs por ano (Figura 4) e o total mensal da ocorrência de JBNs entre 2001 e 2015 (Figura 5). Ressalta-se que a frequência dos JBNs é obtida do ponto de grade mais próximo de cada local. A Figura 1 ilustra essa informação, isto é, a localização das oito cidades em estudo é apresentada juntamente com a posição do ponto de grade das duas reanálises mais próximos delas.

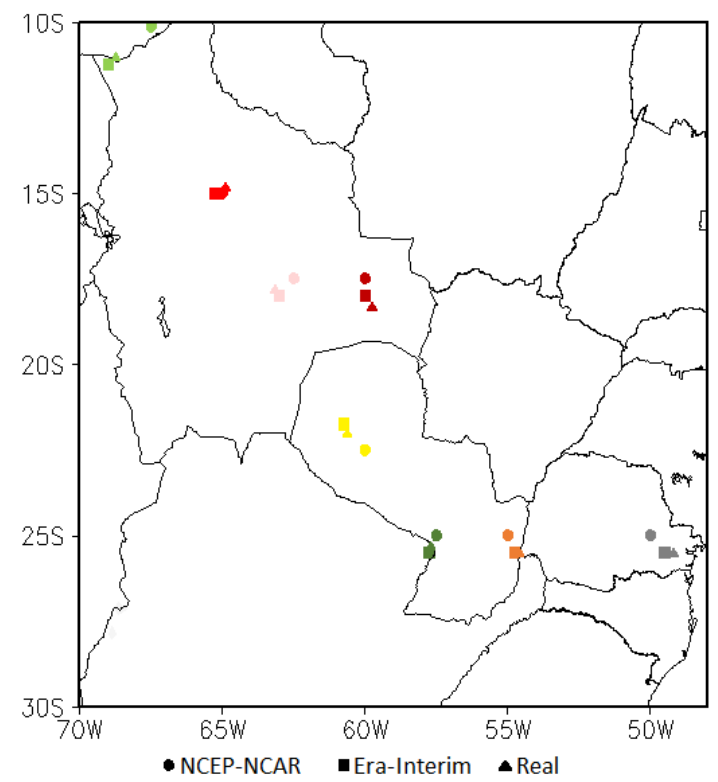

Figura 1 - Pontos de grade das reanálises do NCEP-NCAR (círculo) e da ERA-Interim (quadrado) mais próximos das localidades de radiossondagens (triângulos) utilizados no estudo de Marengo et al. (2004). 
Tabela 2 - Coordenadas geográficas dos municípios utilizados no estudo dos JBNs e dos pontos de grade das reanálises do NCEP-NCAR e da ERA-Interim mais próximos desses. Cada cor indica um município representado na Figura 1.

\begin{tabular}{|c|c|c|c|c|c|c|c|}
\hline \multirow{2}{*}{ Municípios } & \multirow{2}{*}{ Cor } & \multicolumn{3}{|c|}{ Radiossondagens } & NCEP-NCAR & \multicolumn{2}{|c|}{ ERA-Interim } \\
\hline & & Latitude & Longitude & Latitude & Longitude & Latitude & Longitude \\
\hline Asunción & & $-25,3$ & 302,3 & $-25,0$ & 302,5 & $-25,5$ & 302,3 \\
\hline Cobija & & $-11,0$ & 291,3 & $-10,0$ & 292,5 & $-11,3$ & 291,0 \\
\hline Curitiba & & $-25,5$ & 310,8 & $-25,0$ & 310,0 & $-25,5$ & 310,5 \\
\hline $\begin{array}{l}\text { Foz do } \\
\text { Iguaçu }\end{array}$ & & $-25,5$ & 305,4 & $-25,0$ & 305,0 & $-25,5$ & 305,3 \\
\hline $\begin{array}{l}\text { Mariscal } \\
\text { Estigarribia }\end{array}$ & & $-22,0$ & 299,4 & $-22,5$ & 300,0 & $-21,8$ & 299,3 \\
\hline Robore & & $-18,3$ & 300,2 & $-17,5$ & 300,0 & $-18,0$ & 300,0 \\
\hline $\begin{array}{l}\text { Santa Cruz } \\
\text { de la Sierra }\end{array}$ & & $-17,8$ & 296,8 & $-17,5$ & 297,5 & $-18,0$ & 297,0 \\
\hline Trinidad & & $-14,8$ & 295,1 & $-15,0$ & 295,0 & $-15,0$ & 294,8 \\
\hline
\end{tabular}

Para verificar o horário sinótico (00, 06, 12 e 18 UTC) com maior frequência de JBNs, foram elaborados gráficos com o total de JBNs por horário sinótico considerando todo o período em estudo (2001-2015; Figura 7). Por fim, é verificada a relação da frequência de JBNs com os eventos ENOS (Figura 8). Para identificar os meses em que ocorreram eventos de El Niño ou de La Niña, utilizou-se o índice oceânico ONI da National Oceanic and Atmospheric Administration (NOAA). Esse índice considera a média das anomalias da temperatura da superfície do mar (TSM) a cada 3 meses consecutivos na região do Niño $3.4\left(5^{\circ} \mathrm{N}-5^{\circ} \mathrm{S}, 120^{\circ}-170^{\circ} \mathrm{W}\right)$. Quando o ONI apresenta anomalias médias de $+0,5^{\circ} \mathrm{C}$ por cinco trimestres consecutivos tem-se caracterizado um período de El Niño, já quando o ONI apresenta anomalias médias de $-0,5^{\circ} \mathrm{C}$ por cinco trimestres consecutivos tem-se caracterizado um período de La Niña. Para o estudo da relação dos JBNs com o ENOS, a cada três meses acumulou-se o total de ocorrência dos JBNs e, posteriormente, calculou-se a correlação de Pearson do ONI com as séries da frequência de JBNs anual e sazonais: verão (DJF), outono (MAM), inverno (JJA) e primavera (SON). Por brevidade, nas figuras e nas tabelas a seguir o nome dos municípios de Santa Cruz de la Sierra e Mariscal Estigarribia serão abreviados respectivamente, para Santa Cruz e Mariscal.

Todos os cálculos realizados nesse estudo foram programados em linguagem FORTRAN. Os mapas foram elaborados com o software GrADS.

\section{RESULTADOS}

\subsection{PADRÃO ESPACIAL DA CLIMATOLOGIA SAZONAL DO JBN A LESTE DOS ANDES}

A climatologia sazonal da intensidade $\left(\mathrm{m} \mathrm{s}^{-1}\right)$ e direção do vento em 850 hPa, no período de 2001 a 2015, é mostrada na Figura 2. Algumas informações 
podem ser extraídas: o padrão da circulação atmosférica no verão (Figura 2a-b) é diferente do padrão de inverno (Figura 2c-d), mas concordante entre as duas reanálises. No verão, os ventos alísios que adentram a Amazônia, provenientes do oceano Atlântico Tropical Norte, são mais intensos do que no inverno. Esses ventos transportam umidade proveniente do oceano que se associa com a umidade proveniente da evapotranspiração da floresta Amazônica (MARENGO et al., 2004; VERA et al., 2006; DURÁN-QUESADA et al., 2012). Os ventos alísios ao encontrarem a cordilheira dos Andes adquirem uma componente meridional que auxiliará na formação do JBN a leste dos Andes; esse jato transportará umidade dos trópicos para os subtrópicos (Figura 2a-b). Em ambas as reanálises, no verão, a intensidade máxima do JBN é 4-6 $\mathrm{m} \mathrm{s}^{-1}$ e se restringe ao centro-leste da Bolívia.

No inverno, os ventos alísios de nordeste se enfraquecem e os de sudeste (atingindo o nordeste do Brasil) tornam-se mais intensos, característica que está associada com o fortalecimento e expansão para oeste do Anticiclone Subtropical do Atlântico Sul (ASAS). Esse sistema não aparece por completo na Figura 2, mas os ventos do seu setor oeste/noroeste são bem evidentes (Figura 2c-d). A figura também mostra que parte do ASAS (região com ventos mais fracos) atua sobre o sudeste do Brasil, de forma que os ventos mais intensos, que configuram o JBN, ocorrem sobre Mato Grosso, Mato Grosso do Sul, Paraguai e sul do Brasil. Portanto, na estação fria, a formação dos JBNs a leste dos Andes é influenciada pelos ventos do setor oeste do ASAS (Figura 2c-d). Vale destacar que nessa época do ano, a região sudeste do Brasil tem sua estação seca e uma das causas é a inibição da convecção pela atuação do ASAS (REBOITA et al., 2010).

Essa seção pode ser concluída destacando-se que os mecanismos de grande escala que contribuem para a formação dos JBNs a leste dos Andes são diferentes entre verão e inverno. Além disso, em ambas as estações do ano, o JBN registrado na reanálise ERA-Interim apresenta maior extensão meridional do que o registrado na reanálise do NCEP-NCAR. 
a) $\mathrm{V} 850 \mathrm{hPa}$ Verao NCEP-NCAR

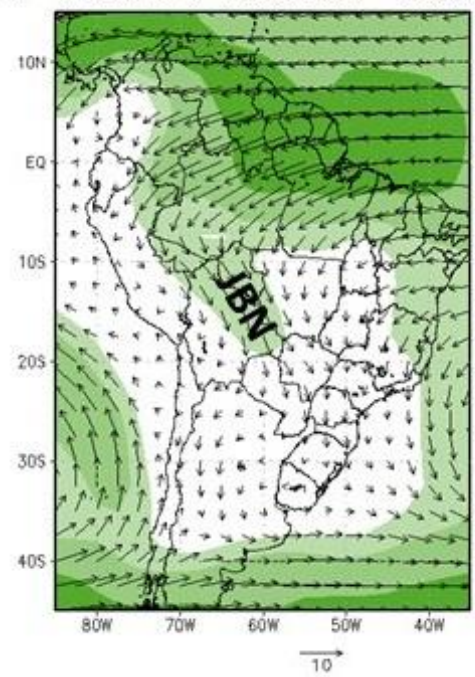

c) V $850 \mathrm{hPo}$ Inverno NCEP-NCAR

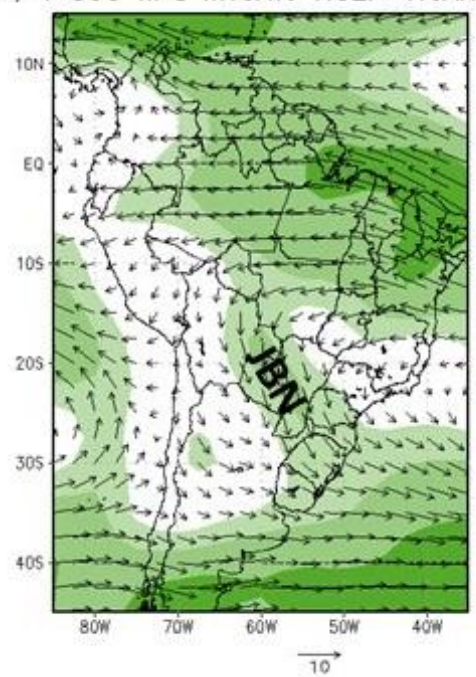

b) $\mathrm{V} 850 \mathrm{hPa}$ Verao ERA-Interim

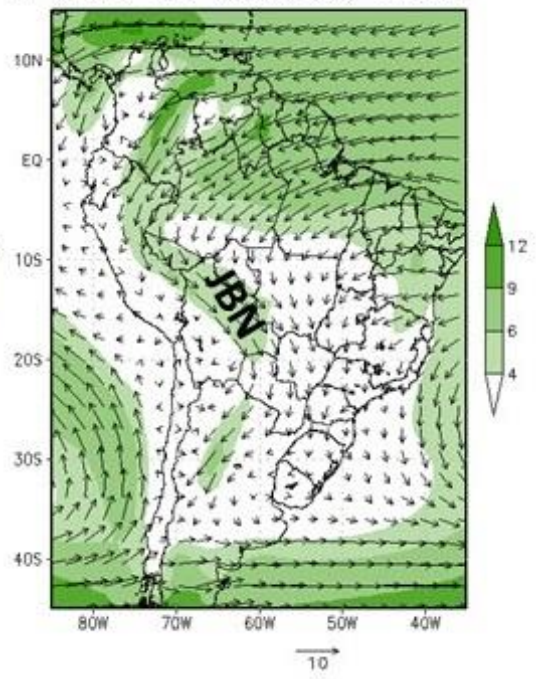

d) $\mathrm{V} 850 \mathrm{hPa}$ Inverno ERA-Interim

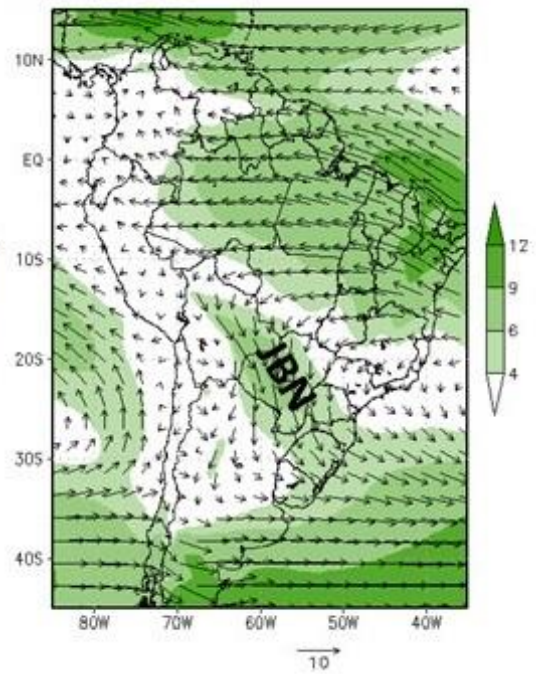

Figura 2 - Climatologia do JBN a leste dos Andes, em $850 \mathrm{hPa}$, no período de 2001 a 2015, obtida das reanálises do $\operatorname{NCEP}-\operatorname{NCAR}(a, c)$ e ERA-Interim e $(b, d)$, para inverno e verão. O campo sombreado indica a intensidade do vento $\left(\mathrm{m} \mathrm{s}^{-1}\right)$ e as setas, a intensidade e direção do vento. O vetor de referência está no rodapé das figuras e corresponde a $10 \mathrm{~m} \mathrm{~s}^{-1}$. O núcleo de maior intensidade dos ventos associados aos jatos está identificado com a sigla JBN.

\subsection{FREQUÊNCIA ANUAL DA OCORRÊNCIA DE JBNS A LESTE DOS ANDES}

Como mencionado na metodologia, o critério 1 de Bonner foi aplicado a todos os pontos de grade das reanálises NCEP-NCAR e ERA-Interim. Com isso, é possível representar os resultados espacialmente. Assim, essa seção apresenta uma comparação da ocorrência total de JBN a leste dos Andes identificados nos pontos de grade de ambas as reanálises, no período de 2001 a 2015, e a diferença entre elas (Figura 3). Como as reanálises possuem diferentes resoluções horizontais, após a identificação do número de JBNs em pontos de grade na reanálise ERA-Interim, tal informação foi interpolada para a mesma 
resolução espacial da reanálise do $\operatorname{NCEP-NCAR~}(2,50)$ para se computar o campo da diferença da frequência de JBNs (Figura 3c). Na Figura 3c, as áreas em tons de verde indicam que há maior frequência de JBNs na reanálise ERA-Interim do que na NCEP-NCAR, enquanto os tons de azul indicam menor frequência.

A frequência de JBNs é maior na reanálise ERA-Interim do que na NCEPNCAR, principalmente na região que se estende do sudeste da Bolívia, passando pelo oeste do Paraguai, até o centro da Argentina (Figura 3b-c). Essa diferença entre as reanálises pode estar associada à resolução espacial dos dados. Como a resolução da reanálise do NCEP-NCAR é de 2,50 (aproximadamente $250 \mathrm{~km}$ ) enquanto a da ERA-Interim é de 0,750 (aproximadamente $75 \mathrm{~km}$ ), essa última consegue representar/resolver melhor as circulações atmosféricas e, portanto, produzir um maior número de JBN. Esse resultado talvez possa ser mais próximo do observado com radiossondagem, já que Marengo et al. (2004) mencionaram que a reanálise do NCEP-NCAR subestima a intensidade e a frequência dos JBN.

No oceano Atlântico Sudoeste, a ERA-Interim também registra maior ocorrência de ventos intensos do que o NCEP-NCAR. Em tal região oceânica, os ventos intensos estão associados com os sistemas transientes (ciclones e anticiclones) ou com os ventos do setor oeste do ASAS.
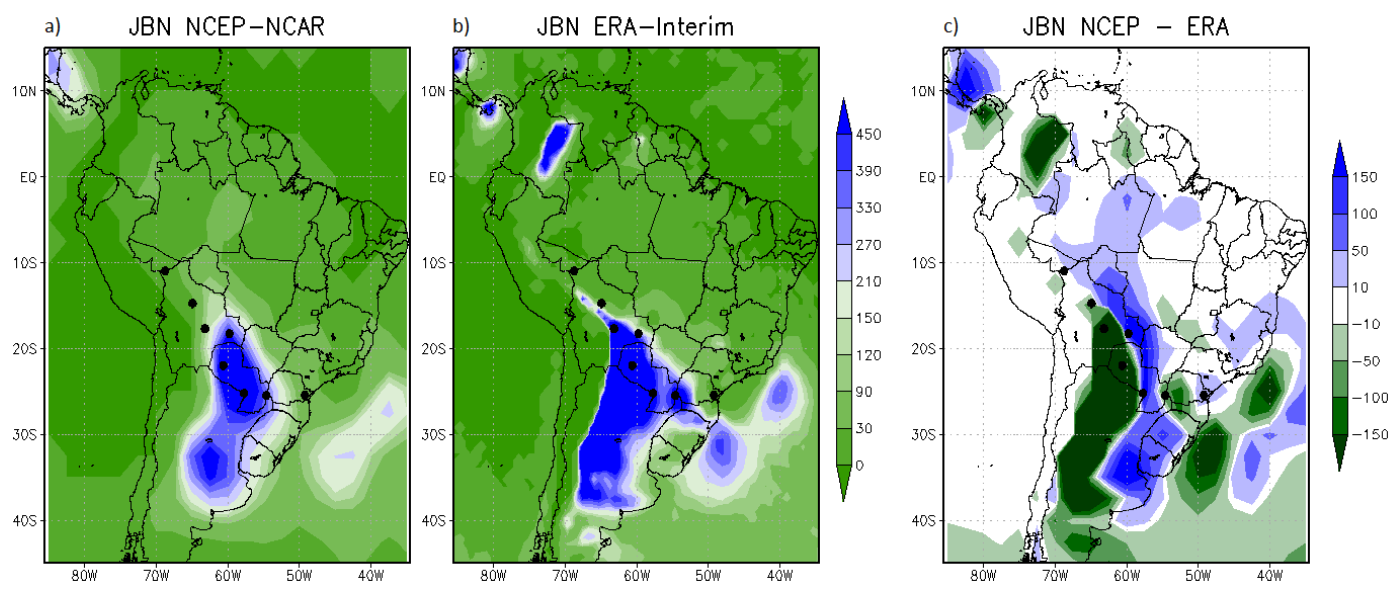

Figura 3 - Número total de JBNs a leste dos Andes identificados com o critério 1 de Bonner no período de 2001 a 2015, considerando cada horário sinótico, para os dados da reanálise I do NCEP-NCAR (a), da reanálise ERA-Interim (b) e da diferença entre NCEPNCAR e ERA-Interim (c). Os pontos em preto indicam a localização dos municípios apresentados na Tabela 1 .

O presente estudo também analisa os JBNs em localidades próximas aos oito municípios mostrados em Marengo et al. (2004), desde o norte da Bolívia até a região sul do Brasil (Figura 1). Da mesma forma que esses autores, os pontos de grade das reanálises não necessariamente coincidem com as coordenadas dos municípios (Tabela 1), mas estão muito próximos delas (Figura 1). Considerando-se as oito localidades e ambas as reanálises, a menor frequência de JBNs a leste dos Andes ocorre nos municípios ao norte da Bolívia (Cobija e Trinidad) e no município de Curitiba, no estado do Paraná, Brasil. A reanálise ERA-Interim apresenta a maior ocorrência anual de JBN em Santa 
Cruz seguida de Mariscal (Figura 4) e os valores obtidos nessas duas localidades são bem maiores do que os da reanálise NCEP-NCAR (Tabela 3). Superestimavas da frequência do JBN com dados da ERA-Interim também são obtidas em Trinidad e Foz do Iguaçu. Nas demais localidades, a reanálise do NCEP-NCAR indica superestimativa da frequência de JBN comparada aos valores da ERA-Interim (Tabela 3). Como em Marengo et al. (2004), a frequência de JBNs em Robore é maior do que em Santa Cruz na reanálise NCEP-NCAR, o que não ocorre com os dados da ERA-Interim.

Também é evidente na Figura 4 que há uma variabilidade interanual na frequência de JBN (há anos com maior frequência de jatos) o que é medido pelo desvio-padrão apresentado na Tabela 3. Em Trinidad, por exemplo, os anos de 2006 e 2007 apresentaram maior ocorrência de JBN, mas essa maior ocorrência não é registrada em outros locais. Portanto, sugere-se que possa ocorrer algum mecanismo local que influencie a frequência de JBN. A seção 3.5 traz uma discussão sobre a influência do ENOS na ocorrência de JBN, o que pode parcialmente explicar a variabilidade interanual desses sistemas.

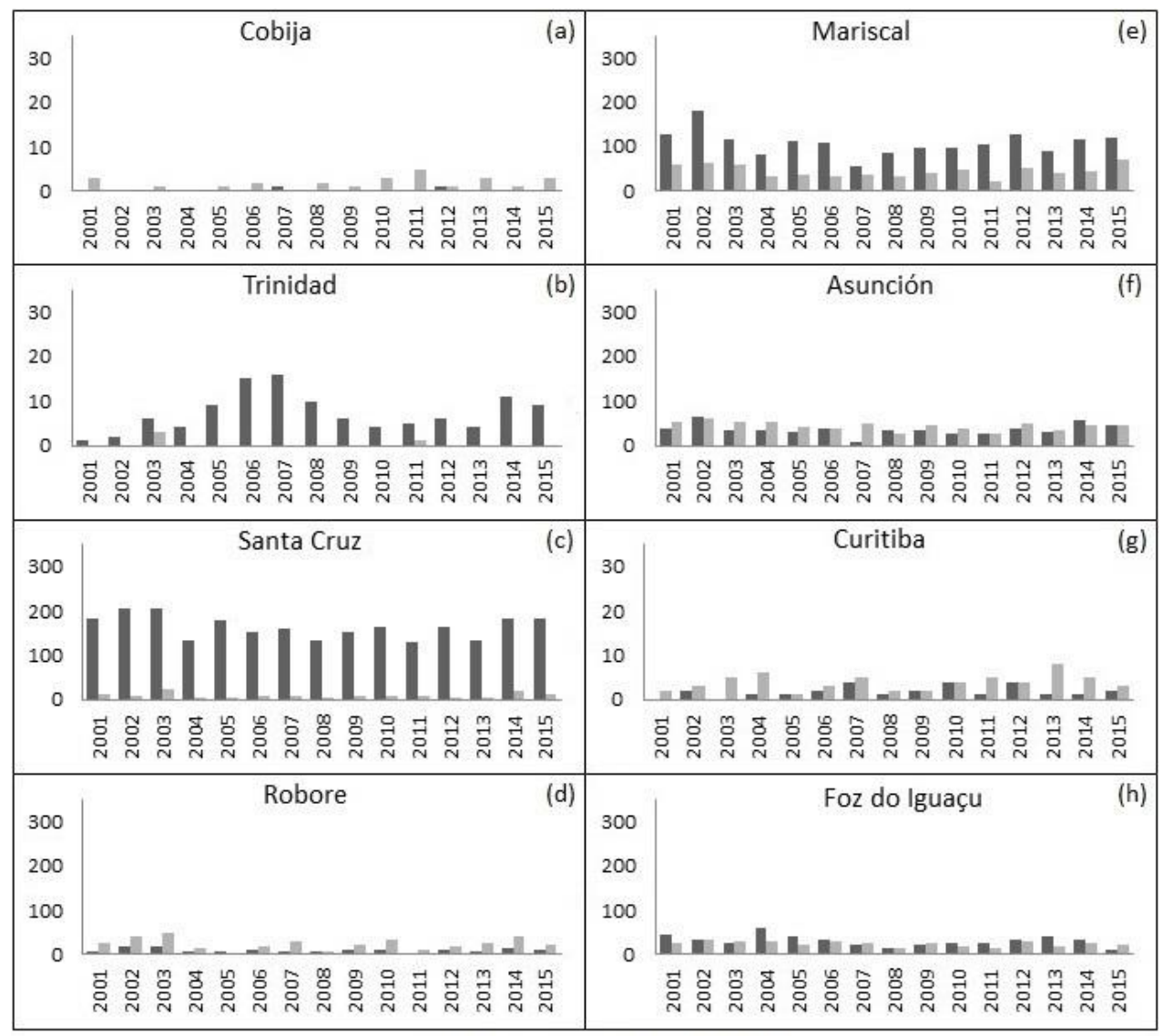

aERA-Interim $=$ NCEP-NCAR

Figura 4 - Número anual de JBN a leste dos Andes identificados com o critério 1 de Bonner, no período de 2001 a 2015. Os critérios de ocorrência do JBN foram obtidos para os pontos de grade das reanálises do NCEP-NCAR (cinza claro) e ERA-Interim (cinza escuro) próximos de Cobija (a), Trinidad (b), Santa Cruz (c), Robore (d), Mariscal (e), Asunción (f), Curitiba ( $g$ ) e Foz do Iguaçu (h). A escala de frequência do vento não é igual em todas as figuras para que seja visualizada a frequência de jatos em locais com baixa ocorrência. 
Tabela 3 - Ocorrência média anual de JBN e respectivo desvio-padrão das reanálises NCEP-NCAR e ERA-Interim e diferença entre as duas, para o período de 2001 a 2015.

\begin{tabular}{|c|c|c|c|c|c|c|}
\hline \multirow{2}{*}{ Municípios } & \multicolumn{2}{|c|}{ NCEP-NCAR } & \multicolumn{2}{|c|}{ ERA-INTERIM } & \multicolumn{2}{|c|}{$\begin{array}{c}\text { Diferença entre as } \\
\text { reanálises (NCEP - } \\
\text { ERA) }\end{array}$} \\
\hline & $\begin{array}{l}\text { Média } \\
\text { anual }\end{array}$ & $\begin{array}{l}\text { Desvio } \\
\text { padrão }\end{array}$ & $\begin{array}{l}\text { Média } \\
\text { anual }\end{array}$ & $\begin{array}{l}\text { Desvio } \\
\text { padrão }\end{array}$ & $\begin{array}{l}\text { Média } \\
\text { anual }\end{array}$ & $\begin{array}{l}\text { Desvio } \\
\text { padrão }\end{array}$ \\
\hline Asunción & 43,6 & 9,7 & 35,8 & 12,9 & 7,8 & $-3,2$ \\
\hline Cobija & 1,7 & 1,4 & 0,1 & 0,3 & 1,6 & 1,1 \\
\hline Curitiba & 3,9 & 1,8 & 1,7 & 1,3 & 2,2 & 0,5 \\
\hline $\begin{array}{l}\text { Foz do } \\
\text { Iguaçu }\end{array}$ & 25,1 & 5,8 & 32,1 & 12,4 & $-7,0$ & $-6,6$ \\
\hline Mariscal & 43,9 & 14,3 & 107,1 & 27,7 & $-63,2$ & $-13,4$ \\
\hline Robore & 24,5 & 12,7 & 10,6 & 4,1 & 13,9 & 8,6 \\
\hline Santa Cruz & 8,7 & 5,7 & 163,9 & 25,2 & $-155,2$ & $-19,5$ \\
\hline Trinidad & 0,3 & 0,8 & 7,2 & 4,4 & $-6,9$ & $-3,6$ \\
\hline
\end{tabular}

\subsection{OCORRÊNCIA MENSAL DE JBN A LESTE DOS ANDES}

A análise por município mostra que, em Cobija (Figura 5a), os JBN a leste dos Andes ocorrem apenas entre a primavera e verão na reanálise do NCEPNCAR e somente em dezembro na reanálise ERA-Interim. Em Trinidad (Figura 5b), os JBN ocorrem preferencialmente no verão, embora os dados da ERAInterim também indiquem uma grande frequência de sistemas no inverno. Em Santa Cruz (Figura 5c) e Robore (Figura 5d), a maior frequência de JBNs ocorre no verão na reanálise do NCEP-NCAR, o que concorda com o estudo de Marengo et al. (2004), e, no inverno, na reanálise ERA-Interim, o que concorda com Nascimento et al. (2016), que utilizaram os dados da reanálise CFSR. Além disso, dos oitos municípios avaliados, em Santa Cruz, a ERA-Interim apresenta a maior frequência de JBN, uma vez que esta localidade está situada onde o JBN é bem configurado tanto no verão quanto no inverno (Figura 2). Embora os quatro municípios mencionados nesta seção estejam na Bolívia, apresentam diferenças na frequência e ciclo anual do JBN. Tal fato está associado com o escoamento atmosférico, pois no norte da Bolívia o JBN só é bem configurado durante o verão (Figura 2). 


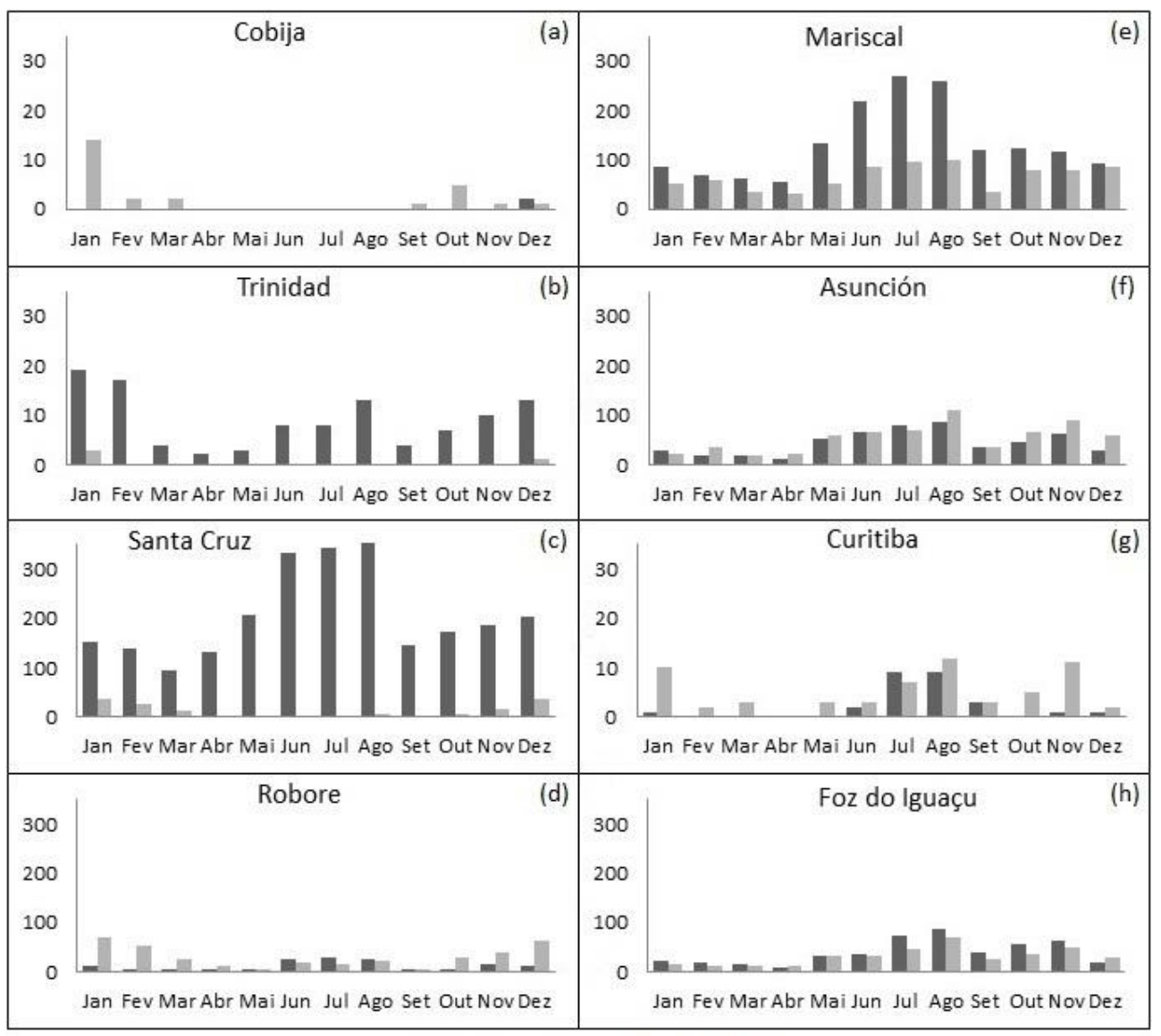

aERA-Interim $n$ NCEP-NCAR

Figura 5 - Número total mensal de JBN a leste dos Andes identificados com o critério 1 de Bonner, no período de 2001 a 2015, nos pontos de grade das reanálises do NCEPNCAR (cinza claro) e da ERA-Interim (cinza escuro) localizados próximos de Cobija (a), Trinidad (b), Santa Cruz (c), Robore (d), Mariscal (e), Asunción (f), Curitiba (g) e Foz do Iguaçu $(h)$.

Marengo et al. (2004) ressaltam que a frequência de JBN a leste dos Andes é maior no inverno nas localidades situadas em latitudes mais altas do que $20^{\circ} \mathrm{S}$ (Mariscal Estigarribia, Assunção, Curitiba e Foz do Iguaçu) e maior no verão nas localidades situadas em latitudes mais baixas. Esse padrão é quase totalmente reproduzido no presente estudo (Figura 5 e Tabela 4) exceto pelo fato da reanálise ERA-Interim mostrar maior frequência de jatos no inverno em Santa Cruz $\left(\sim 18^{\circ} \mathrm{S}\right)$. Esse é um resultado interessante já que outra reanálise pertencente ao NCEP, a reanálise CFSR, também mostra maior frequência de JBN no inverno, em Santa Cruz. Esse último resultado foi obtido por Nascimento et al. (2016), porém os autores não indicam as possíveis causas da diferença na sazonalidade em relação à reanálise do NCEP-NCAR. Sugere-se aqui que esse resultado possa ser influenciado pela resolução das reanálises já que a ERAInterim e CFSR possuem maior resolução horizontal do que a do NCEP-NCAR.

A sazonalidade registrada na ocorrência do JBN pode estar relacionada com a sazonalidade da circulação de grande escala. No verão, os ventos alísios 
de nordeste mais intensos do que no inverno podem favorecer a formação do JBN, enquanto que no inverno, são os ventos do setor oeste do ASAS que se encontram atuando sobre o centro da América do Sul, o que não é típico no verão (MARENGO et al., 2004; REBOITA et al., 2010; JUNQUAS et al., 2016).

Tabela 4 - Meses de menor e de maior frequência de JBN registrado nas reanálises do NCEP-NCAR e ERA-Interim, no período de 2001 a 2015.

\begin{tabular}{lcccc}
\hline \multirow{2}{*}{ Municípios } & \multicolumn{2}{c}{ Mês de menor ocorrência } & \multicolumn{2}{c}{ Mês de maior ocorrência } \\
\cline { 2 - 5 } & NCEP-NCAR & ERA-INTERIM & NCEP-NCAR & ERA-INTERIM \\
\hline Asunción & Março & Abril & Agosto & Agosto \\
Cobija & Abril & Abril & Janeiro & Dezembro \\
Curitiba & Abril & Abril & Agosto & Agosto \\
Foz do Iguaçu & Abril & Abril & Agosto & Agosto \\
Mariscal & Abril & Abril & Agosto & Julho \\
Robore & Setembro & Fevereiro & Janeiro & Julho \\
Santa Cruz & Maio & Março & Janeiro & Agosto \\
Trinidad & Abril & Abril & Janeiro & Janeiro \\
\hline
\end{tabular}

A fim de ilustrar o impacto da resolução horizontal das diferentes reanálises na climatologia dos JBNs a leste dos Andes, os JBNs foram identificados em Santa Cruz de la Sierra, no período entre 1990-1999, com o critério 1 de Bonner aplicado à reanálise NCEP-NCAR, NCEP-DOE, ERA-40, ERAInterim e CFSR (Figura 6). As três primeiras possuem resolução horizontal de 2,50, a ERA-Interim possui resolução de $0,75^{\circ}$ e a CFSR possui resolução de $0,5^{\circ}$.

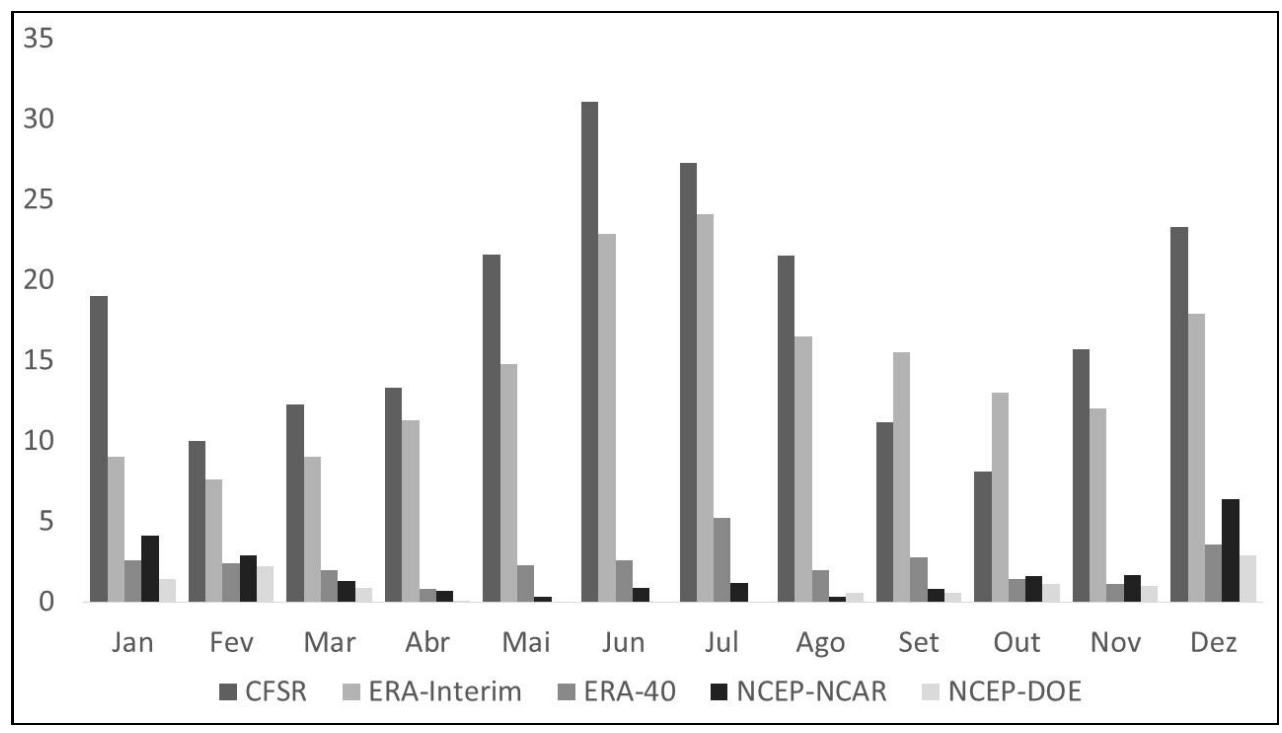

Figura 6 - Média mensal da ocorrência de JBNs a leste dos Andes identificados com o critério 1 de Bonner em cinco reanálises, no período de 1990 a 1999, em Santa Cruz de la Sierra. 
A Figura 6 mostra que a frequência de JBNs é proporcional à resolução horizontal das reanálises. Isto é, quanto melhor a resolução dos dados, maior é o número de sistemas identificados. Esse resultado concorda com a climatologia de outros sistemas atmosféricos, como a dos ciclones extratropicais (REBOITA et al., 2018), em que diferentes reanálises são comparadas. Outra informação interessante na Figura 6 é que independente do período de análise, as reanálises do NCEP-NCAR e NCEP-DOE mostram maior ocorrência de JBNs no verão em Santa Cruz de la Sierra, enquanto as demais, no inverno. Novamente, a resolução horizontal dos dados impacta nos resultados climatológicos.

\subsection{HORÁRIO PREFERENCIAL DE OCORRÊNCIA DO JBN A LESTE DOS ANDES}

A Figura 7 mostra o total de JBN, entre 2001 a 2015, por horário sinótico, enquanto a Tabela 5 apresenta o horário com maior frequência desse sistema no verão, inverno e anualmente. No verão, nos municípios em estudo, há uma preferência pela ocorrência de JBN às 06 UTC em ambas as reanálises. Já no inverno, na reanálise do NCEP-NCAR, os JBNs são mais frequentes às 12 UTC, exceto em Mariscal, cuja maior frequência ocorre às 06 UTC. Na reanálise ERA-Interim, os JBNs são mais frequentes às 06 UTC em Santa Cruz, Robore e Mariscal. Portanto, nota-se que, em geral, os eventos de JBN possuem maior ocorrência entre a madrugada e início da manhã. Essa característica de ocorrência do JBN principalmente de madrugada e início da manhã também foi mostrada por Marengo et al. (2004), Silva et al. (2010) e Nascimento et al. (2016). Entre novembro e fevereiro, Marengo et al. (2004) mostraram que em Cobija, Santa Cruz, Mariscal e Foz do Iguaçu os eventos de JBN são mais frequentes às 06 UTC e que, entre maio e agosto, predominam no horário das 06 UTC e 12 UTC.

Uma possível explicação para que o JBN a leste dos Andes ocorrer a preferencialmente entre 06 e 12 UTC é a influência das circulações de brisa de vale- montanha. À noite, próximo à superfície, o escoamento será da montanha para o vale, mas em níveis mais afastados da superfície a célula de circulação terá escoamento da região do vale para a montanha. Assim, a força devido ao gradiente horizontal de pressão ocorre de leste para oeste. Com a força de Coriolis deflete o escoamento do ar para a esquerda, no HS, faz aparecer uma componente mais forte para o sul, o que favorece a circulação característica do JBN. Sabe-se que a circulação de brisa é um fenômeno pouco influenciado pela força de Coriolis, mas como os Andes possuem uma grande extensão meridional, as circulações de brisa alcançam extensões maiores e a força de Coriolis acaba por atuar no escoamento. Tanto no presente estudo quanto no de Marengo et al. (2004) é mostrado que no verão há preferência pela ocorrência do JBN às 06 UTC enquanto que no inverno, entre 06 e 12 UTC. De acordo com Marengo et al. (2004), a maior variabilidade na hora preferencial de ocorrência do JBN no inverno pode estar associada à maior influência de sistemas sinóticos transientes que acabam modulando o JBN. 


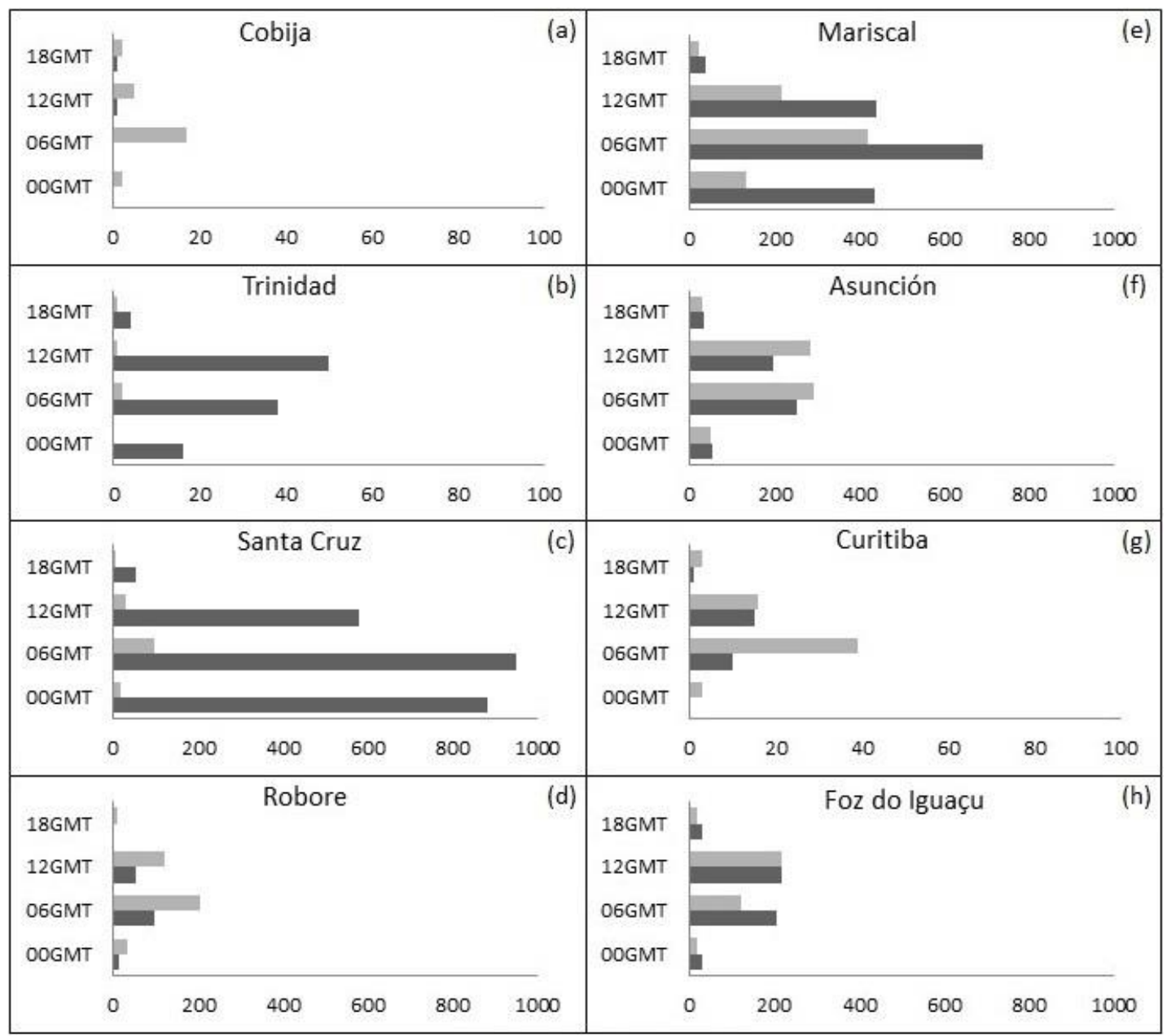

EERA-Interim $=$ NCEP-NCAR

Figura 7 - Frequência de eventos de JBN a leste dos Andes nos horários sinóticos 00, 06, 12 e 18 UTC, de 2001 a 2015, nos pontos de grade das reanálises do NCEP-NCAR (cinza claro) e ERA-Interim (cinza escuro) localizados próximos de Cobija (a), Trinidad (b), Santa Cruz (c), Robore (d), Mariscal (e), Asunción (f), Curitiba (g) e Foz do Iguaçu (h). 
Tabela 5 - Horário preferencial de ocorrência de JBN no ano, verão e inverno para os dados da reanálise I do NCEP-NCAR e reanálise do ERA-Interim, de 2001 a 2015.

\begin{tabular}{|c|c|c|c|c|c|c|}
\hline \multirow[b]{2}{*}{ Municípios } & \multicolumn{2}{|c|}{ Ano } & \multicolumn{2}{|c|}{ Verão } & \multicolumn{2}{|c|}{ Inverno } \\
\hline & $\begin{array}{l}\text { NCEP- } \\
\text { NCAR }\end{array}$ & $\begin{array}{c}\text { ERA- } \\
\text { INTERIM }\end{array}$ & $\begin{array}{l}\text { NCEP- } \\
\text { NCAR }\end{array}$ & $\begin{array}{c}\text { ERA- } \\
\text { INTERIM }\end{array}$ & $\begin{array}{l}\text { NCEP- } \\
\text { NCAR }\end{array}$ & $\begin{array}{c}\text { ERA- } \\
\text { INTERIM }\end{array}$ \\
\hline Asunción & $\begin{array}{l}06 \\
\text { UTC }\end{array}$ & 06 UTC & $\begin{array}{c}06 \\
\text { UTC }\end{array}$ & 06 UTC & $\begin{array}{l}12 \\
\text { UTC }\end{array}$ & 06 UTC \\
\hline Cobija & $\begin{array}{l}06 \\
\text { UTC }\end{array}$ & 12 UTC & $\begin{array}{c}06 \\
\text { UTC }\end{array}$ & 12 UTC & - & - \\
\hline Curitiba & $\begin{array}{l}06 \\
\text { UTC }\end{array}$ & 12 UTC & $\begin{array}{c}06 \\
\text { UTC }\end{array}$ & 06 UTC & $\begin{array}{c}12 \\
\text { UTC }\end{array}$ & 12 UTC \\
\hline $\begin{array}{l}\text { Foz do } \\
\text { Iguaçu }\end{array}$ & $\begin{array}{c}12 \\
\text { UTC }\end{array}$ & 12 UTC & $\begin{array}{c}06 \\
\text { UTC }\end{array}$ & 12 UTC & $\begin{array}{c}12 \\
\text { UTC }\end{array}$ & 12 UTC \\
\hline Mariscal & $\begin{array}{l}06 \\
\text { UTC }\end{array}$ & 06 UTC & $\begin{array}{c}06 \\
\text { UTC }\end{array}$ & 06 UTC & $\begin{array}{l}06 \\
\text { UTC }\end{array}$ & 06 UTC \\
\hline Robore & $\begin{array}{l}06 \\
\text { UTC }\end{array}$ & 06 UTC & $\begin{array}{l}06 \\
\text { UTC }\end{array}$ & 06 UTC & $\begin{array}{l}12 \\
\text { UTC }\end{array}$ & 06 UTC \\
\hline Santa Cruz & $\begin{array}{l}06 \\
\text { UTC }\end{array}$ & 06 UTC & $\begin{array}{l}06 \\
\text { UTC }\end{array}$ & 06 UTC & $\begin{array}{c}12 \\
\text { UTC }\end{array}$ & 06 UTC \\
\hline Trinidad & $\begin{array}{l}06 \\
\text { UTC }\end{array}$ & 12 UTC & $\begin{array}{l}06 \\
\text { UTC }\end{array}$ & 12 UTC & - & 12 UTC \\
\hline
\end{tabular}

Obs.: Ausência de horários preferenciais indica que não há ocorrência dos JBNs em determinada estação do ano.

\subsection{VARIABILIDADE INTERANUAL DA OCORRÊNCIA DE JBN A LESTE DOS ANDES}

Para verificar uma possível relação do fenômeno ENOS com a frequência de JBNs a leste dos Andes, foram elaborados gráficos com os totais trimestrais do evento nos oito municípios considerados. Na Figura 8, a cor vermelha indica a ocorrência de El Niño e a azul, de La Niña. Uma análise geral da Figura 8 indica que há certa correlação linear entre a maior frequência de JBNs com episódios de El Niño. Este aspecto está em acordo com os resultados de Silva e Ambrizzi (2006) e Silva et al. (2009), que indicam que nos eventos El Niño há intensificação dos ventos alísios de nordeste sobre o continente o que, consequentemente, favorece os JBNs. Associa-se a maior frequência de JBNs com eventos de El Niño devido à maior intensidade e frequencia de anomalias ciclônicas em baixos níveis da atmosfera, próximas ao sudeste da América do Sul. A principal contribuição das anomalias ciclônicas para a maior frequência dos JBNs está associada à intensificação do escoamento de noroeste, da região central da Bolívia para o sul do Brasil (CAMPETELLA; VERA, 2002; CUADRA; DA ROCHA, 2006).

Também foi computada a correlação linear entre o número total de JBNs em cada estação do ano e a fase do ENOS. Na Tabela 6, correlação positiva indica que há maior número de JBNs quando o ONI é positivo, quando há El Niño; ou indica que há menor número de JBNs quando o ONI é negativo, quando há La Niña. Correlações significativas $(p=0,05)$ são destacadas em negrito. No verão, em Foz do Iguaçu e Santa Cruz há correlação positiva e significativa do ONI com os dados da reanálise ERA-Interim, enquanto os dados do NCEP-NCAR mostram correlação positiva e significativa em Assunção. Tanto os dados do NCEP como os dados do Era-Interim não apresentam correlação 
linear significativa com o ONI durante o outono. Esse resultado repete-se no inverno na reanálise do NCEP-NCAR. Já na reanálise ERA-Interim, as correlações são positivas e significativas em Assunção e Mariscal. Na primavera, ambas as reanálises indicam que o El Niño tem contribuição para a maior frequência de JBNs em Santa Cruz e Mariscal. Por fim, considerando uma análise anual, a correlação é positiva e significativa em Assunção, Foz do Iguaçu, Mariscal e Santa Cruz na reanálise ERA-Interim e em Assunção, Foz do Iguaçu, Mariscal e Robore na reanálise do NCEP-NCAR. Já em Cobija, as duas reanálises indicam correlação negativa, mas não significativa. Os resultados em termos anuais são bastante relevantes uma vez que quando há ocorrência de El Niño, há anomalias positivas de precipitação nos municípios mencionados (RAO; HADA, 1990; GRIMM et al., 1998; SILVA, 2009) e isso, geralmente, tem associação com o transporte de umidade dos trópicos para os subtrópicos pelo JBN.

Tabela 6 - Correlação linear de Pearson entre o ONI e a ocorrência de JBN segundo os dados da ERA-Interim e do NCEP-NCAR, para as escalas anual e sazonal (DJF, MAM, JJA, SON), de 2001 a 2015.

\begin{tabular}{clcccccccc}
\hline \multicolumn{2}{c}{ Período } & Asunción & Cobija & Curitiba & $\begin{array}{c}\text { Foz do } \\
\text { Iguaçu }\end{array}$ & Mariscal & Robore & $\begin{array}{c}\text { Santa } \\
\text { Cruz }\end{array}$ & Trinidad \\
\hline \multirow{2}{*}{ DJF } & ERA & 0,26 & $-0,39$ & 0,01 & $\mathbf{0 , 5 2}$ & 0,39 & 0,14 & $\mathbf{0 , 5 4}$ & $-0,02$ \\
& NCEP & $\mathbf{0 , 6 1}$ & $-0,08$ & 0,26 & $\mathbf{0 , 5 9}$ & 0,44 & $\mathbf{0 , 5 3}$ & 0,35 & 0,19 \\
\hline \multirow{2}{*}{ MAM } & ERA & $-0,09$ & - & - & 0,24 & $-0,05$ & $-0,27$ & $-0,08$ & $-0,18$ \\
& $N$ NCEP & 0,19 & $-0,13$ & $-0,24$ & 0,04 & 0,25 & 0,34 & $-0,05$ & - \\
\hline \multirow{2}{*}{ JJA } & ERA & $\mathbf{0 , 6 1}$ & - & 0,11 & 0,14 & $\mathbf{0 , 5 4}$ & $-0,15$ & 0,16 & $-0,02$ \\
& NCEP & 0,49 & - & 0,28 & 0,27 & 0,42 & 0,43 & 0,45 & - \\
\hline \multirow{2}{*}{ SON } & ERA & 0,45 & - & $-0,38$ & $-0,01$ & $\mathbf{0 , 5 7}$ & 0,40 & $\mathbf{0 , 5 5}$ & 0,35 \\
& $N$ NCEP & 0,18 & $-0,15$ & $-0,34$ & 0,19 & $\mathbf{0 , 5 8}$ & 0,38 & $\mathbf{0 , 5 3}$ & - \\
\hline \multirow{2}{*}{ Ano } & ERA & $\mathbf{0 , 4 0}$ & $-0,20$ & $-0,02$ & $\mathbf{0 , 2 1}$ & $\mathbf{0 , 3 7}$ & 0,19 & $\mathbf{0 , 3 5}$ & 0,03 \\
& NCEP & $\mathbf{0 , 4 4}$ & $-0,14$ & 0,03 & $\mathbf{0 , 3 4}$ & $\mathbf{0 , 4 9}$ & $\mathbf{0 , 3 0}$ & 0,17 & 0,06 \\
\hline
\end{tabular}

Obs.: Valores estatisticamente significativos, $p=0,05$, estão em negrito. A ausência de valores de correlação indica que o município não apresenta ocorrência de JBN para o respectivo período. 

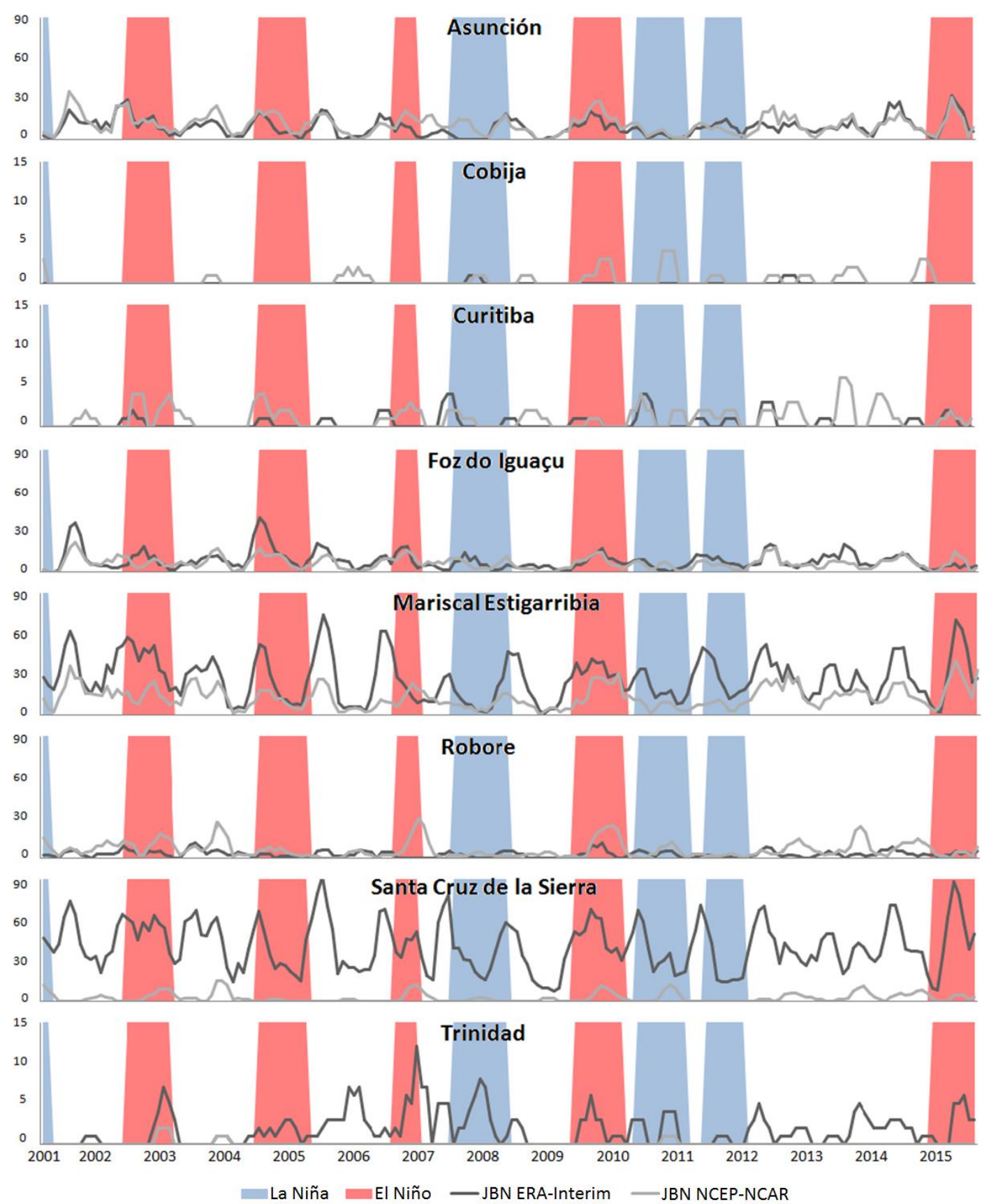

Figura 8 - Ocorrência trimestral de JBN a leste dos Andes entre 2001 e 2015. Os anos de El Niño (vermelho) e La Niña (azul claro). A quantidade de eventos de JBN foi computada para os pontos de grade das reanálises do NCEP-NCAR (cinza claro) e da ERA-Interim (cinza escuro).

\section{CONCLUSÕES}

Neste estudo, a ocorrência de jatos de baixos níveis a leste dos Andes, no período de 2001 a 2015, foi determinada através do critério 1 de Bonner, 
com base em dois conjuntos de reanálises: a reanálise I do NCEP-NCAR, com resolução horizontal de 2,50, e ERA-Interim do ECMWF, com resolução horizontal de $0,75^{\circ}$. O objetivo foi identificar as diferenças de ocorrência anual e sazonal de eventos de JBNs nos dados com diferentes resoluções horizontais.

A formação dos JBNs a leste dos Andes ainda não é totalmente compreendida. Sabe-se que esses jatos existem mesmo na ausência das montanhas andinas (GANDU; GEISLER, 1991; INSEL et al., 2010; REBOITA et al., 2012; JUNQUAS et al., 2016), uma vez que estão associados aos gradientes horizontais de temperatura do ar/pressão entre trópicos e subtrópicos, sendo também influenciados por sistemas transientes nos subtrópicos e extratrópicos (SUGAHARA et al., 1994; REBOITA, 2008). De acordo com (MARENGO et al., 2004), os JBNs a leste dos Andes apresentam diferenças sazonais. No verão, a formação dos JBNs é influenciada pelos ventos alísios de nordeste que adentram a região Amazônica e se dirigem ao sul devido ao aquecimento diabático continental. No inverno, a formação dos JBNs é influenciada pela circulação do setor oeste do ASAS, que nessa época do ano é mais intenso e extenso (com seu setor oeste sobre o sudeste do Brasil). Em geral, comparando-se os dados das duas reanálises, os JBNs têm maior intensidade e extensão meridional na reanálise ERA-Interim do que na reanálise do NCEP-NCAR, sendo mais evidente no verão. Além disso, a reanálise ERA-Interim expande para oeste a frequência de JBNs comparada à do NCEP-NCAR.

A frequência anual de ocorrência dos JBNs foi investigada em oito localidades situadas ao longo da trajetória desses sistemas. Em Santa Cruz há cerca de $94 \%$ menos registros de JBNs na reanálise do NCEP-NCAR do que na reanálise ERA-Interim. Na reanálise ERA-Interim, os três municípios com maior frequência de JBNs são Santa Cruz, Mariscal e Asunción; já no NCEP-NCAR são Mariscal, Asunción e Foz do Iguaçu.

Marengo et al. (2004) mostrou que a reanálise do NCEP-NCAR registra maior ocorrência de JBNs nos municípios localizados em latitudes mais tropicais (Cojiba, Trindad, Santa Cruz e Robore) no verão, enquanto nos situados próximos aos subtrópicos (Mariscal, Assunção, Curitiba e Foz do Iguaçu), no inverno. Esses resultados são parcialmente reproduzidos no presente estudo, pois na ERA-Interim há maior frequência de JBNs no inverno em Santa Cruz e Robore. Nessa mesma estação do ano, a reanálise ERA-Interim registra grande frequência de JBNs em Trindad. Nascimento et al. (2016), utilizando a reanálise CFSR, também encontraram a maior frequência de JBNs em Santa Cruz durante o inverno. Para elucidar o impacto da resolução horizontal das reanálises na climatologia dos JBNs a leste dos Andes, foi realizada uma comparação da climatologia de 5 reanálises (NCEP-NCAR, NCEP-DOE, ERA-40, ERA-Interim e CFSR) no período de 1990 a 1999 em Santa Cruz de la Sierra. Concluiu-se que a ocorrência de JBNs é proporcional à resolução horizontal dos dados: há maior frequência de sistemas na reanálise $\operatorname{CFSR}\left(0,5^{\circ}\right)$ e menor nas reanálises NCEPNCAR e NCEP-DOE $\left(2,5^{\circ}\right)$. Além disso, a sazonalidade dos JBNs também é afetada pela resolução horizontal dos dados. Enquanto nas reanálises NCEPNCAR e NCEP-DOE há maior frequência de JBNs no verão em Santa Cruz de la Sierra, nas demais isso é registrado no inverno.

Quanto ao horário preferencial de ocorrência dos JBNs, verifica-se que maior ocorrência entre a madrugada e o início da manhã. No verão, ambas as reanálises mostram maior frequência de JBNs às 06 UTC, enquanto que no 
inverno, na reanálise do NCEP-NCAR, os JBNs são mais frequentes às 12 UTC, exceto em Mariscal (06 UTC). Na reanálise ERA-Interim, os JBNs são mais frequentes às 06 UTC em Santa Cruz, Robore e Mariscal.

Os resultados do presente estudo também indicam possível relação física da ocorrência de JBNs com o fenômeno ENOS. Em anos de El Niño há maior frequência de JBNs. Por fim, ressalta-se que a maior diferença entre as duas reanálises ocorre nos municípios de Santa Cruz e Trinidad.

\section{AGRADECIMENTOS}

Os autores agradecem ao NCEP-NCAR e ECMWF a disponibilidade dos conjuntos de dados das reanálises usadas, e, ao CNPq e FAPEMIG pelo apoio financeiro.

\section{REFERÊNCIAS}

BEEBE, R. G.; BATES, F. C. A mechanism for assisting in the release of convective instability. Monthly Weather Review, v. 83, p. 1-10, 1955.

BERBERY, E. H.; BARROS, V. R. The hydrological cycle of the La Plata basin in South America, Journal Hydrometeorology, v. 3, p. 630-645, 2002.

BONNER, W. D. Climatology of the Low Level Jet. Monthly Weather Review, v. 96, p. 833-850, 1968.

CAMPETELLA, C.; VERA, C. The influence of the Andes Mountains on the South American low-level flow. Geophysical Research Letters, v. 29, n. 17, p. 1826, 2002.

CUADRA, S. V.; DA ROCHA, R. P. Simulação Numérica do Clima de Verão Sobre o Sudeste do Brasil e sua Variabilidade. Revista Brasileira de Meteorologia, v. 21, p. 271-282, 2006.

DEE, D. P.; UPPALA, S. M.; SIMMONS, A. J.; BERRISFORD, P.; POLI, P.; KOBAYASHI, S.; ANDRAE, U.; BALMASEDA, M. A.; BALSAMO, G.; BAUER, P.; BECHTOLD, P.; BELJAARS, A.; VAN DE BERG, L.; BIDLOT, J.; BORMANN, N.; DELSOL, C.; DRAGANI, R.; FUENTES, M.; GEER, A. J.; HAIMBERGER, L.; HEALY, S. B.; HERSBACH, H.; HÓLM, E. V.; ISAK-SEN, L.; KALLBERG, P.; KÖHLER, M.; MATRICARDI, M.; MCNALLY, A. P.; MONGE-SANZ, B. M.; MORCRETTE, J. J.; PARK, B. K.; PEUBEY, C.; DE ROSNAY, P.; TAVOLATO, C.; THÉPAUT, J. N.; VITART, F. The ERA-Interim reanalysis: Configuration and performance of the data assimilation system. Quarterly Journal of the Royal Meteorological Society, v. 137, n. 656, p. 553-597, 2011.

DURÁN-QUESADA, A. M.; REBOITA, M.; GIMENO, L. Precipitation in tropical America and the associated sources of moisture: a short review. Hydrological Sciences Journal, v. 57, n. 4, p. 612-624, 2012.

GANDU, A. W.; GEISLER, J. E. A primitive equations model study of the effect of topography on the summer circulation over tropical South America. Journal of the Atmospheric Sciences, v. 48, p. 1822-1836, 1991. 
GRIMM, A. M.; FERRAZ, S. E. T.; GOMES, J. Precipitation anomalies in Southern Brazil associated with El Niño and La Niña events. Journal of Climate, v. 11, p. 2863-2880, 1998.

INSEL, N.; POULSEN, C. J.; EHLERS, T. A. Influence of the Andes Mountains on South American moisture transport, convection, and precipitation. Climate Dynamics, v. 35, p. 1477-1492, 2010.

JIANG, X.; LAU, N.-C.; HELD, I. M.; PIOSHAY, J. J. Mechanisms of the Great Plains Low-Level Jet as Simulated in an AGCM. Journal of the Atmospheric Sciences, v. 64, p. 532-547, 2007.

JUNQUAS, C.; LI, L.; VERA, C. S.; LE TREUT, H.; TAKAHASHI. K. Influence of South America orography on summertime precipitation in Southeastern South America. Climate Dynamics, v. 46, p. 3941-3963, 2016.

KALNAY, E. E. et al. NCEP/NCAR 40-year Reanalysis Project. Bulletin of the American Meteorological Society, v. 77, p. 437-471, 1996.

MARENGO, J. A.; DOUGLAS, M.; SILVA DIAS, P. The South American low-level jet east of the Andes during the 1999 LBA-TRMM and LBA-WET AMC campaign. Journal of geophysical research, v. 107, p. 8079, 2002.

MARENGO, J. A.; SOARES, W. R.; SAULO, C.; NICOLINI, M. Climatology of the low-level jet east of the Andes as derived from the NCEP-NCAR reanalyses: characteristics and temporal variability. Journal of Climate, v. 17, n. 12, p. 2261-2280, 2004.

NASCIMENTO, M. G.; HERDIES, D. L. SOUZA, D. O. The South American Water Balance: The Influence of Low-Level Jets. Journal of Climate, v. 39, p. 14291449, 2016.

NOGUÉS-PEAGLE, J.; MO, K. C. Alternating wet and dry conditions over South America during summer. Monthly Weather Review, v. 125, n. 2, p. 279-291, 1997.

RAHN, D. A.; GARREAUD, R. D. A synoptic climatology of the near-surface wind along the west coast of South America. International Journal of Climatology, $v$. 34, p. 780-792, 2013.

RAO, V. B.; HADA, K. Characteristics of rainfall over Brazil: annual variations and connections with the sourthern oscillations. Theoretical and Applied Climatology, v. 42, p. 81-91, 1990.

REBOITA, M. S. Ciclones Extratropicais sobre o Atlântico Sul: Simulação Climática e Experimentos Numéricos de Sensibilidade. 2008. 316 p. Tese (Doutorado em Meteorologia) - Universidade de São Paulo, São Paulo, 2008.

REBOITA, M. S.; GAN. M. A.; ROCHA, R. P.; AMBRIZZI, T. Regimes de precipitação na América do Sul: uma revisão bibliográfica. Revista brasileira de meteorologia, v. 25, n. 2, p. 185-204, jun. 2010.

REBOITA, M. S.; DA ROCHA, R. P.; AMBRIZZI, T. Dynamic and Climatological Features of Cyclonic Developments over Southwestern South Atlantic Ocean. In: B. VERESS; J. SZIGETHY. (Org.). Horizonts in Earth Science Research, v. 6, p. 135-160, 2012. 
SAHA, S.; MOORTHI, S.; PAN, H.; WU, X.; WANG, J... The NCEP Climate Forecast SystemReanalysis. Bulletin of the American Meteorological Society, $v$. 91, p. 1015-1057, 2010.

SELUCHI, M.; MARENGO, J. A. Tropical-midlatitude Exchange of air masses during summer and winter in South America: Climatic aspects and extreme events. International Journal of Climatology, v.20, p. 1167-1190, 2000.

SILVA, G. A. M. Evolução dos eventos El Niños em fases distintas da Oscilação Decadal do Pacífico: impactos no Jato de Baixos Níveis a Leste dos Andes e nos ciclones extratropicais da América do Sul. 2009. 76 f. Tese (Doutorado em Meteorologia) - Universidade de São Paulo, São Paulo, 2009.

SILVA, G. A. M.; AMBRIZZI, T. Inter-El Niño variability and its impact on the South American low-level jet east of the Andes during austral summer - two case studies. Advances in Geosciences, v. 6, p. 283-287, 2006.

SILVA, G. A. M.; AMBRIZZI, T.; MARENGO, J. A. Observational evidences on the modulation of the South American Low Level Jet east of the Andes according the ENSO variability. Annales Geophysicae, v. 27, p. 645-657, 2009.

SILVA, M. C. L.; DA ROCHA, R. P.; YNOUE, R. Y. Climatic simulations of the eastern Andes low-level jet and its dependency on convective parameterizations. Meteorol Atmos Phys, v. 108, p. 9-27, 2010.

SILVA DIAS, M. A. F. Sistemas de Mesoescala e Previsão de Tempo a Curto Prazo. Revista Brasileira de Meteorologia, v. 2, p. 133-150, 1987.

STENSRUD, D. Importance of low-level jets to climate: A review. Journal of Climate, v. 9, p.1698-1711, 1996.

SUGAHARA, S.; ROCHA, R. P.; RODRIGUES, M. L. Condições atmosféricas de grande escala associadas a jato de baixos níveis na América do Sul. In: Congresso Brasileiro de Meteorologia, 8, 1994, Belo Horizonte, Anais... São José dos Campos: Sociedade Brasileira de Meteorologia, 1994. p. 573-577.

VERA, C.; HIGGINS, W. AMADOR, J.; AMBRIZZI, T.; GARREAUD, R.; GOCHIS, D.; GUTZLER, D.; LETTENMAIER, D.; MARENGO, J. A.; MECHOSO, C. R.; NOGUÉS-PAEGLE, J.; SILVA DIAS, P. L.; ZHANG, C. Towards a unified view of the American Monsoon systems. Journal of Climate, v. 19, p. 4977-5000, 2006. 